\title{
USO DE URINA DE VACA E HÚMUS DE MINHOCA NO CRESCIMENTO DE ALFACE
}

\section{USO DE ORINA DE VACA Y HUMUS DE LOMBRIZ Y EN CRECIMIENTO DE LECHUGA}

\section{USE OF URINE OF COW AND EARTHWORM HUMUS IN THE GROWTH LETTUCE}

\author{
Alexandro de Figueiredo ANDRADE ${ }^{1}$ \\ Mário Leno Martins VÉRAS ${ }^{2}$ \\ Lunara de Sousa ALVES ${ }^{3}$ \\ Danila Lima de ARAÚJO \\ Raimundo ANDRADE ${ }^{5}$
}

RESUMO: A alface é uma hortaliça folhosa muito utilizada na dieta alimentar, sendo muito cultivada na agricultura familiar, no entanto, muitos agricultores utilizam adubação química nesta cultura. Neste sentido, objetivou-se com este estudo avaliar o uso de urina de vaca e húmus de minhoca no crescimento de alface. Adotou-se o delineamento experimental inteiramente casualizado (DIC), com 10 tratamentos, no arranjo fatorial 5 x 2, com 4 repetições totalizando 40 plantas experimentais. Estudou-se 5 doses de urina de vaca: $\left(D_{1}=0\right.$ $\mathrm{mL}, \mathrm{D}_{2}=10 \mathrm{~mL}, \mathrm{D}_{3}=20 \mathrm{~mL}, \mathrm{D}_{4}=30 \mathrm{~mL}$ e $\mathrm{D}_{5}=40 \mathrm{~mL}$ ) e duas proporções de húmus de minhoca: $\left(\mathrm{P}_{1}=50 \%\right.$ de solo $+50 \%$ de húmus de minhoca e $\mathrm{P}_{2}=25 \%$ de solo $+75 \%$ de húmus de minhoca). Verificou-se que todas as variáveis foram influenciadas significativamente pelas doses de urina de vaca a nível de significância de $(\mathrm{p}<0,01)$. Já para a influência das proporções de húmus de minhoca não houve efeitos significativos para as variáveis analisadas. As mudas de alface responderam significativamente as doses de urina de vaca, com destaque na dose de $40 \mathrm{~mL}$. O húmus de minhoca não teve resposta significativa quando utilizado como substrato.

Palavras-chave: Lactuca sativa L., fertilizante orgânico, substrato.

\footnotetext{
${ }^{1}$ Graduado em Ciências Agrárias, Universidade Estadual da Paraíba - UEPB/Campus IV - CEP 58884-000 Catolé do Rocha - Paraíba - Brasil. afigueiredoandrade@bol.com.br

${ }^{2}$ Mestrando em agronomia, Universidade Federal da Paraíba - UFPB/Campus II - Areia - Paraíba - Brasil. mario.deus1992@bol.com.br

${ }^{3}$ Graduada em Ciências Agrárias, Universidade Estadual da Paraíba - UEPB/Campus IV - CEP 58884-000 Catolé do Rocha - Paraíba - Brasil. lunara_alvesuepb@ hotmail.com

${ }^{4}$ Mestre em Engenharia Agrícola, Universidade Federal de Campina Grande - UFCG - Campina Grande Paraíba - Brasil. danilalimaraujo@ hotmail.com

${ }^{5}$ Prof. Doutor do Departamento de Agrárias e Exatas, Universidade Estadual da Paraíba - UEPB/Campus IV CEP 58884-000 - Catolé do Rocha - Paraíba - Brasil. raimundoarndrade@uepb.edu.br
} 
RESUMEN: La lechuga es una verdura de hoja ampliamente utilizado en la dieta, siendo muy cultivado en granjas familiares, sin embargo, muchos agricultores utilizan fertilizantes químicos en esta cultura. En este sentido, el objetivo de este estudio fue evaluar el uso de la orina de vaca y lombricompuesto en el crecimiento de la lechuga. Hemos adoptado un diseño completamente al azar (DCA) con 10 tratamientos en un arreglo factorial 5 x 2, con cuatro repeticiones totalizando 40 plantas experimentales. 5 Se estudió la orina dosis vaca: $\left(D_{1}=0\right.$ $\mathrm{mL}, \mathrm{D}_{2}=10 \mathrm{~mL}, \mathrm{D}_{3}=20 \mathrm{~mL}, \mathrm{D}_{4}=30 \mathrm{~mL}$ e $\mathrm{D}_{5}=40 \mathrm{~mL}$ ) y dos proporciones humus de lombriz: $\left(\mathrm{P}_{1}=50 \%\right.$ suelo $+50 \%$ humus de lombriz y $\mathrm{P}_{2}=25 \%$ del suelo $+75 \%$ humus de lombriz). Se encontró que todas las variables fueron significativamente afectados por nivel de dosis orina de vaca de la significación $(\mathrm{p}<0,01)$. En cuanto a la influencia de las relaciones de humus de lombriz no hubo efectos significativos para las variables analizadas. Las plántulas de lechuga responde significativamente las dosis orina de vaca, especialmente a una dosis de $40 \mathrm{~mL}$. El humus de lombriz no tenía ninguna respuesta significativa cuando se utiliza como un sustrato.

Palabras chaves: Lactuca sativa L., fertilizante orgânico, sustrato.

\begin{abstract}
The lettuce is a leafy vegetable widely used in the diet, being very grown on family farms, however, many farmers use chemical fertilizers in this culture. In this sense, the aim of this study was to evaluate the use of cow urine and earthworm compost on lettuce growth. We adopted a completely randomized design (CRD) with 10 treatments in a factorial arrangement $5 \times 2$, with four replications totalizing 40 experimental plants. 5 was studied doses cow urine: $\left(\mathrm{D}_{1}=0 \mathrm{~mL}, \mathrm{D}_{2}=10 \mathrm{~mL}, \mathrm{D}_{3}=20 \mathrm{~mL}, \mathrm{D}_{4}=30 \mathrm{~mL}\right.$ e $\left.\mathrm{D}_{5}=40 \mathrm{~mL}\right)$ and two earthworm humus proportions: $\left(\mathrm{P}_{1}=50 \%\right.$ soil $+50 \%$ earthworm humus and $\mathrm{P}_{2}=25 \%$ soil + $75 \%$ earthworm humus). It was found that all variables were significantly affected by cow urine dose level of significance $(\mathrm{p}<0,01)$. As for the influence of earthworm humus ratios there were no significant effects for the analyzed variables. The lettuce seedlings significantly answered the cow urine doses, especially at a dose of $40 \mathrm{~mL}$. The earthworm humus had no significant response when used as a substrate.
\end{abstract}

Keywords: Lactuca sativa L., organic fertilizer, substrate.

\title{
INTRODUÇÃO
}

A cultura da alface (Lactuca sativa L.) é nativa de regiões de clima temperado. Por ser uma hortaliça folhosa, apresenta sensibilidade à temperatura e a luminosidade elevada podendo seu potencial genético se comprometer favorecendo a redução do ciclo e assim diminuindo a qualidade do produto a ser comercializado (CRUZ et al., 2011). Se destaca nacional e mundialmente devido seu consumo na dieta alimentar. Possui diversas propriedades nutritivas (ABREU et al., 2010). 
O cultivo orgânico apresenta diversas vantagens ao meio ambiente Moeskopsa et al. (2010), à eficiência energética Souza et al. (2008) e a qualidade superior dos alimentos Silva et al. (2011), aumentando ainda a renda de quem produz alimentos orgânicos.

Dentre os fertilizantes orgânicos, a urina de vaca é derivada da atividade pecuária, sendo disponível na maioria das propriedades rurais e de baixa custo de aquisição. É considerada ainda fonte de nutrientes para as plantas, devido a riqueza em elementos minerais, além disso, não há risco de problemas à saúde de quem utiliza este produto, estando praticamente pronta para uso, bastando apenas acrescentar água (PESAGRO-RIO, 2002).

Autores como Véras et al. (2014) e Araújo et al. (2014) também trabalharam com a aplicação de urina de vaca em plantas de alface, pinha e maracujá e obtiveram resultados positivos.

O húmus de minhoca é um adubo orgânico muito utilizado como fonte de nutrientes para as plantas, para quem deseja uma produção orgânica, é aplicado nas hortaliças na forma sólida (ARTEAGA et al., 2007).

Este insumo agrícola pode ser uma opção de adubação na produção orgânica, podendo substituir o uso de substratos comerciais, visto que não é permitida a nutrição das mudas com adubos minerais solúveis na produção orgânica. Rodrigues et al., (2012) mostram que para a formação de mudas de boa qualidade, é essencial a escolha do substrato bem como a proporção e a combinação de substratos.

Araújo Neto et al. (2009) também citam que o húmus de minhoca, por ser rico em fósforo, cálcio e potássio, pode fazer parte da composição de substratos para produção de mudas orgânicas.

Oliveira et al, (2013) trabalhando com húmus de minhoca associado a composto orgânico para a produção de mudas de tomate obtiveram bons resultados com esse substrato. Estudos feitos por Araújo et al. (2013) trabalhando com produção de mudas de melão cantaloupe em diferentes tipos de substratos e obtiveram melhores resultados com substratos contendo húmus de minhoca.

Neste sentido, objetivou-se com este estudo avaliar o uso de urina de vaca e húmus de minhoca no crescimento de alface.

\section{MATERIAIS E MÉTODOS}

O experimento foi desenvolvido, em condições de ambiente protegido (casa de vegetação), no Centro de Ciências Humanas e Agrárias, na Escola Agrotécnica do Cajueiro, pertencente á Universidade Estadual da Paraíba - UEPB, Campus-IV, distando $02 \mathrm{~km}$ da sede 
do município de Catolé do Rocha/PB (6²0’38”S; 3744’48”W) e 275 metros de altitude. O clima do município, de acordo com a classificação de Koppen, é do tipo BSW', ou seja, quente e seco do tipo estepe, com temperatura média mensal superior a $18^{\circ} \mathrm{C}$, durante todo o ano.

O delineamento experimental adotado foi o inteiramente casualizado (DIC), com 10 tratamentos, no esquema fatorial 5 x 2, com 4 repetições totalizando 40 plantas experimentais. Foram estudados os efeitos de 5 doses de urina de vaca: $\left(\mathrm{D}_{1}=0 \mathrm{~mL}, \mathrm{D}_{2}=10 \mathrm{~mL}, \mathrm{D}_{3}=20 \mathrm{~mL}\right.$, $\mathrm{D}_{4}=30 \mathrm{~mL}$ e $\left.\mathrm{D}_{5}=40 \mathrm{~mL}\right)$, aplicadas via solo e duas proporções de húmus de minhoca: $\left(\mathrm{P}_{1}=\right.$ $50 \%$ de solo $+50 \%$ de húmus de minhoca e $\mathrm{P}_{2}=25 \%$ de solo $+75 \%$ de húmus de minhoca).

A água utilizada na irrigação apresentou condutividade elétrica de $0,8 \mathrm{dS} / \mathrm{m}$. A análise da água foi realizada pelo Laboratório de Irrigação e Salinidade (LIS) do Centro de Tecnologia e Recursos Naturais da Universidade Federal de Campina Grande - UFCG e apresentou as seguintes características químicas: $\mathrm{pH}=7,53 ; \mathrm{Ca}=2,30\left(\mathrm{cmol}_{\mathrm{c}} / \mathrm{dm}^{3}\right) . \mathrm{Mg}=1,56$ $\left(\mathrm{cmol}_{\mathrm{C}} / \mathrm{dm}^{3}\right) ; \mathrm{Na}=4,00\left(\mathrm{cmol}_{\mathrm{d}} / \mathrm{dm}^{3}\right) ; \mathrm{K}=0,02\left(\mathrm{cmol}_{\mathrm{C}} / \mathrm{dm}^{3}\right) ;$ Cloreto $=3,90\left(\mathrm{cmol}_{\mathrm{C}} / \mathrm{dm}^{3}\right) ;$ Carbonato $=0,57\left(\mathrm{cmol}_{\mathrm{c}} / \mathrm{dm}^{3}\right) ;$ Bicarbonato $=3,85\left(\mathrm{cmol}_{\mathrm{c}} / \mathrm{dm}^{3}\right) ; \mathrm{RAS}=2,88\left(\mathrm{mmol}_{\mathrm{c}} \mathrm{L}^{-1}\right)^{1 / 2} \mathrm{e}$ Classificação Richards (1954) com $\mathrm{C}_{3} \mathrm{~S}_{1}$.

O solo utilizado foi classificado como franco argilo arenoso, foram coletadas amostras na camada de 0 a $20 \mathrm{~cm}$ em área localizada no campus da UEPB. Da amostra de solo utilizada para o preenchimento dos sacos de polietileno foi retirada uma sub-amostra para ser analisada quimicamente e apresentou as seguintes características: $\mathrm{Ca}=4,63\left(\mathrm{cmol}_{\mathrm{c}} / \mathrm{dm}^{3}\right) ; \mathrm{Mg}=2,39$ $\left(\mathrm{cmol}_{\mathrm{C}} / \mathrm{dm}^{3}\right) ; \mathrm{Na}=0,30\left(\mathrm{cmol}_{\mathrm{C}} / \mathrm{dm}^{3}\right) ; \mathrm{K}=0,76\left(\mathrm{cmol}_{\mathrm{C}} / \mathrm{dm}^{3}\right) ;$ Soma de bases $-\mathrm{SB}=8,08$ $\left(\mathrm{cmol}_{\mathrm{C}} / \mathrm{dm}^{3}\right) ; \mathrm{H}=0,00\left(\mathrm{cmol}_{\mathrm{C}} / \mathrm{dm}^{3}\right) ; \mathrm{Al}=0,00\left(\mathrm{cmol}_{\mathrm{C}} / \mathrm{dm}^{3}\right) ; \mathrm{CTC}=8,08$ e Matéria orgânica $=$ $1,88 \%$.

A urina de vaca utilizada no experimento foi coletada de vacas em lactação, de rebanho leiteiro da Escola Agrotécnica do Cajueiro - EAC, município de Catolé do Rocha - PB, pertencente à Universidade Estadual da Paraíba. Para a obtenção dos tratamentos, a urina de vaca foi diluída em água a $1 \%$, sendo aplicada via solo.

Os tratamentos com urina de vaca começaram aos 21 dias após emergência (DAE).

A análise química da urina utilizada constou os seguintes atributos: $\mathrm{N}$ Total $=0,28 \%$; $\mathrm{pH}=6,7 ; \mathrm{P}$ Total $=0,48 \% ; \mathrm{K}=1 \% ; \mathrm{Ca}=0,03 \% ; \mathrm{Mg}=0,04 \% ; \mathrm{MO}=79,27 \%$ e Umidade $=$ $95,9 \%$.

O húmus de minhoca que foi utilizado como substrato foi feito a análise química e apresentou as seguintes características: 
Tabela 1. Atributos químicos do húmus de minhocas Vermelha da Califórnia utilizada para formação de substrato. Catolé do Rocha - PB, UEPB, 2014.

\begin{tabular}{lc}
\hline ATRIBUTOS QUÍMICOS & VALORES \\
\hline $\mathrm{Ph} \mathrm{H}_{2} \mathrm{O}(1: 2,5)$ & 7,38 \\
Condutividade Elétrica (dS/m) & 2,11 \\
Cálcio (meq/100 g de solo) & 35,40 \\
Magnésio (meq/100 g de solo) & 19,32 \\
Sódio (meq/100 g de solo) & 1,82 \\
Potássio (meq/100 g de solo) & 1,41 \\
$\mathrm{~S}$ (meq/100 g de solo) & 57,95 \\
Hidrogênio (meq/100 g de solo) & 0,00 \\
Alumínio (meq/100 g de solo) & 0,00 \\
T (meq/100 g de solo) & 57,95 \\
Carbonato de Cálcio Qualitativo & Presente \\
Fósforo Assimilável (meq/100 g de solo) & 55,14
\end{tabular}

Laboratório de Irrigação e salinidade (LIS) do centro de Tecnologia e Recursos Naturais da Universidade Federal de campina Grande - UFCG. Catolé do Rocha - PB, UEPB, 2014.

O semeio foi realizado diretamente no saquinho utilizando-se cinco sementes distribuídas e distanciadas de forma equidistante na profundidade de $2 \mathrm{~cm}$. Aos 20 dias após emergência (DAE) realizou-se um desbaste com a finalidade de se deixar apenas as plantas mais desenvolvidas. Durante a condução do experimento, foram efetuadas capinas manuais, conforme as necessidades de manutenção da cultura no limpo.

Aos 60 dias após emergência (DAE) as mudas foram coletadas e avaliadas as seguintes variáveis: comprimento da raiz, peso verde da folha, peso verde total, teor de água e relação raiz parte aérea.

O comprimento da raiz foi medido com uma régua graduada em centímetros.

O peso verde da folha foi determinado pesando-o separadamente, com o auxílio de uma balança de precisão sendo realizado imediatamente após a retirada do material de campo.

O peso verde total foi obtido somando-se todas as partes verdes da planta (caule, folha e raiz).

O teor de água (TA) nos tecidos, considerado mais preciso (envolve o "peso túrgido"), o que seria um indicativo do "status" de água na planta (PEIXOTO e PEIXOTO, 2004). Essa quantidade de água foi calculada pela fórmula:

$$
\mathrm{TA}=\frac{\mathrm{MF}-\mathrm{MS}}{\mathrm{MF}} * 100
$$


Em que: $\mathrm{MF}=$ massa fresca em gramas, $\mathrm{MS}=$ massa seca, $\mathrm{TA}=$ Teor de água

A relação raiz parte aérea foi calculada pela fórmula:

$$
\mathrm{RPA}=\mathrm{FPA}+\mathrm{FR} \quad \text { eq. } 2
$$

Em que: FPA = fitomassa da parte aérea, $\mathrm{FR}$ = fitomassa da raiz e RPA = relação raiz parte aérea.

Os dados foram submetidos à análise de variância (Teste F). Em caso de significância, as médias foram comparadas pelo teste Tukey a 1 e 5\% de significância de probabilidade, conforme Ferreira (2007).

\section{RESULTADOS E DISCUSSÃO}

Pode-se verificar na Tabela 1 que todas as variáveis foram influenciadas significativamente pelas doses de urina de vaca a nível de significância de $(p<0,01)$, todas as variáveis analisadas e expostas na tabela se enquadraram ao tipo de regressão quadrática crescente. Já para a influência das proporções de húmus de minhoca não houve efeitos significativos para as variáveis analisadas. Não houve interação entre os fatores doses de urina de vaca x proporções de urina de vaca. Os coeficientes de variação oscilaram entre 9,80 a 19,27\% sendo considerados de baixo a médio conforme Pimentel Gomes (2000).

Tabela 1. Resumo das análises de variância referente ao comprimento da raiz (CR), peso verde da folha (PVF), peso verde total (PVT), teor de água (TA) e relação raiz parte aérea (RPA) plantas de pinha cultivadas sob urina de vaca em função de substratos orgânicos.

\begin{tabular}{|c|c|c|c|c|c|c|}
\hline Fonte de variação & GL & & Quadrados & Médios & & \\
\hline & & $\mathrm{CR}$ & PVF & PVT & TA & RPA \\
\hline Doses de urina de vaca & 4 & $37,3 * *$ & $3118,7 * *$ & $5423 * *$ & $8419,4 * *$ & $3169,9 * *$ \\
\hline Regressão Linear & 1 & $35,1 *$ & $5848,2 * *$ & $10649,1 * *$ & $19593,8 * *$ & $7031,5 * *$ \\
\hline Regressão Quadrática & 1 & $55,7 *$ & $4104,3 * *$ & $8418,2 * *$ & $6240,1 * *$ & $2546 * *$ \\
\hline Proporções de húmus de minhoca & 1 & $12,1^{\mathrm{ns}}$ & $70,2^{\mathrm{ns}}$ & $409,6^{\mathrm{ns}}$ & $11^{\mathrm{ns}}$ & $378,2^{\mathrm{ns}}$ \\
\hline Interação $(\mathrm{D} \times \mathrm{P})$ & 4 & $9,9^{\mathrm{ns}}$ & $791,7^{\mathrm{ns}}$ & $468,4^{\mathrm{ns}}$ & $962,2^{\mathrm{ns}}$ & $2440,6^{\mathrm{ns}}$ \\
\hline Resíduo & 30 & 6,1 & 98,6 & 164,5 & 241 & 190,3 \\
\hline Desvio de regressão & 2 & 29,2 & 1261,3 & 1312,5 & 24 & 1551,1 \\
\hline $\mathrm{CV}(\%)$ & - & 19,27 & 9,80 & 10,95 & 17,66 & 14,59 \\
\hline
\end{tabular}

CV: Coeficiente de variação; GL: Grau de liberdade, *, ** significativo 5 e a $1 \%$, respectivamente, e ${ }^{\text {ns }}$ não significativo, pelo teste $\mathrm{F}$

Observa-se que o comprimento da raiz foi influenciado estatisticamente pelas doses de urina de vaca imposto a ele, se comportando de forma quadrática crescente, onde o valor máximo foi encontrado na maior dose com $16,5 \mathrm{~cm}$ de comprimento correspondendo a dose 
de $40 \mathrm{~mL}$ (figura 1). Diferentemente de Véras et al (2014) trabalhando com substratos e fertilização orgânica em plântulas de pinheira, observaram que a solução a base de urina de vaca não tiveram efeitos significativos. O efeito enraizador da urina de vaca também foi demonstrado experimentalmente quando se utilizou o produto a $50 \%$ em mudas de abacaxi (GADELHA et al., 2009).

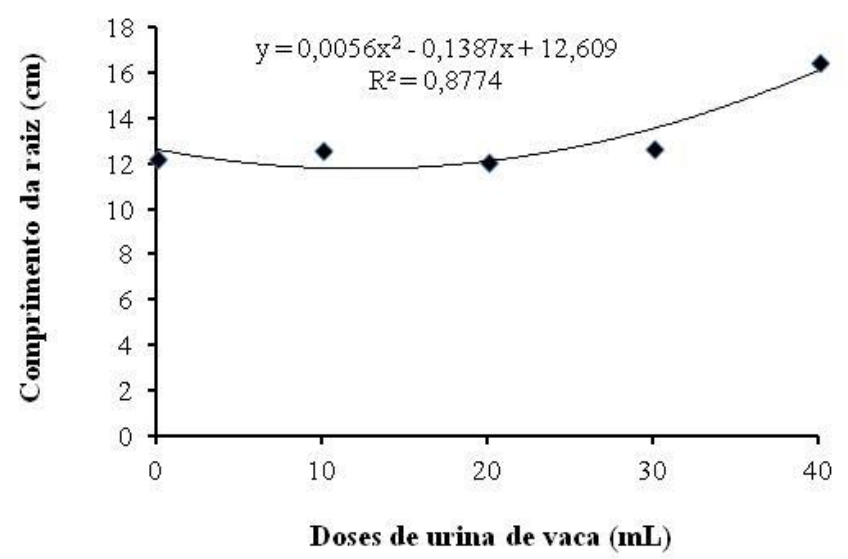

Figura 1: Efeito de doses de urina de vaca no comprimento da raiz de alface.

As doses de urina de vaca influenciaram significativamente o peso verde da folha, se enquadrando no tipo de regressão quadrática com comportamento convexo, com significância de $(\mathrm{p}<0,01)$, onde o maior valor encontrado foi na dosagem máxima de $40 \mathrm{~mL}$ com 129,1 g, em comparação com a dose de $10 \mathrm{~mL}$ com o menor resultado de 109,8 g (figura 2). Os resultados desse trabalho diferem de Véras et al., (2014) estudando o efeito de substratos e fertilização orgânica em plântulas de pinheira onde não obtiveram efeitos significativos com a aplicação de urina de vaca, no entanto, a maior dose proporcionou os maiores valores para o peso verde da folha.

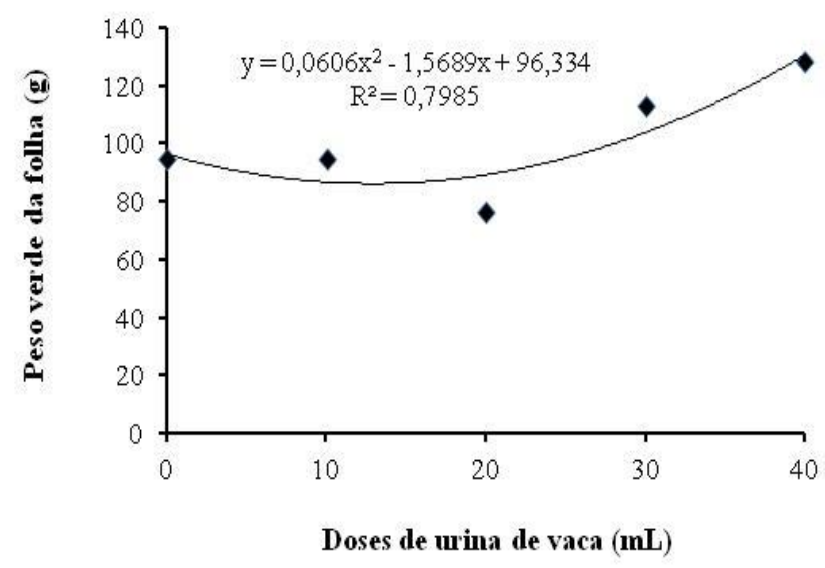

Figura 2: Efeito de doses de urina de vaca no peso verde da folha de alface. 
Observa-se que o peso verde total foi influenciado estatisticamente pelas doses de urina de vaca, se comportando de forma quadrática crescente, onde o valor máximo foi encontrado na maior dose com 158,2 g correspondendo a dose de $40 \mathrm{~mL}$ (figura 3). Resultados semelhantes foram obtidos por Araújo et al (2014) estudando níveis de água disponível e doses de urina de vaca no desenvolvimento do meloeiro cantaloupe e observaram que houve influência significativa a nível de $1 \%$ para a fitomassa fresca total com a aplicação da dose 60 $\mathrm{mL}$ de urina de vaca.

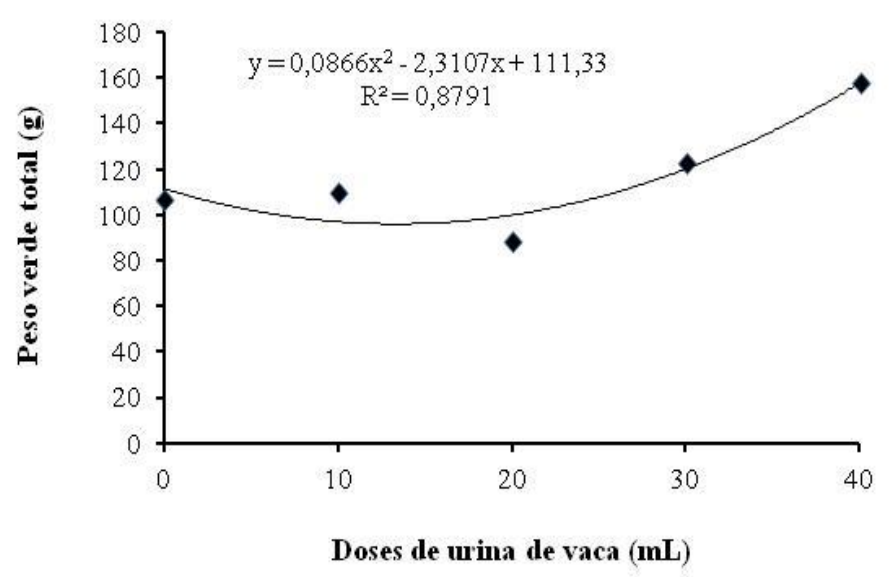

Figura 3: Efeito de doses de urina de vaca no peso verde total de alface.

Observa-se que o teor de água nas plantas foi influenciado significativamente pelas doses de urina de vaca, apresentando significância a nível de $(\mathrm{p}<0,01)$ se enquadrando ao tipo de regressão quadrática crescente, onde o melhor resultado foi encontrado na dose máxima de $40 \mathrm{~mL}$ (figura 4). Os resultados obtidos neste estudo para o teor de água diferem dos encontrados por Araújo et al. (2014) trabalhando com mudas de maracujá sob doses de urina de vaca e obtiveram os melhores resultados para o teor de água sem a aplicação de urina de vaca. 


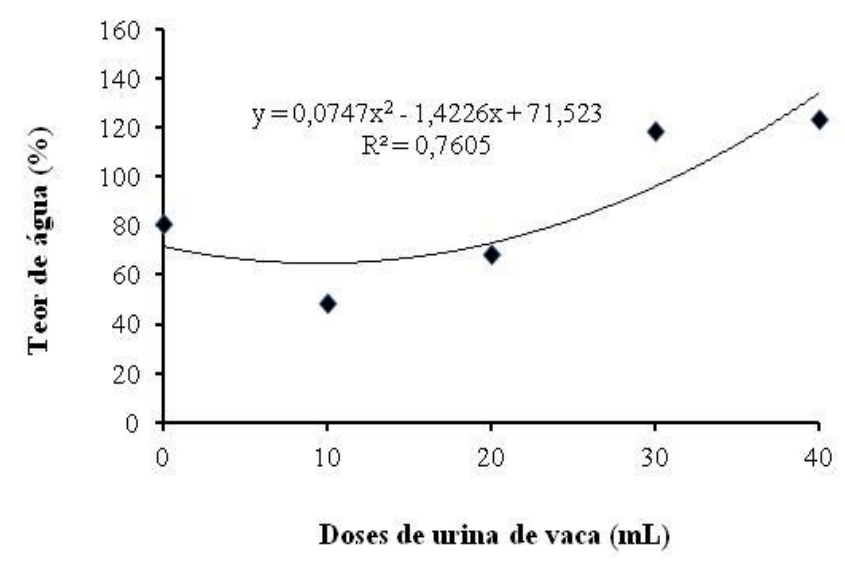

Figura 4: Efeito de doses de urina de vaca no teor de água de alface.

Pode-se perceber para a relação raiz parte aérea uma resposta polinomial quadrática crescente, onde ao aumentar gradativamente as doses de urina de vaca foi observado um aumento na relação raiz parte aérea, com o melhor resultado obtido na dose máxima $(40 \mathrm{~mL})$ (figura 5).

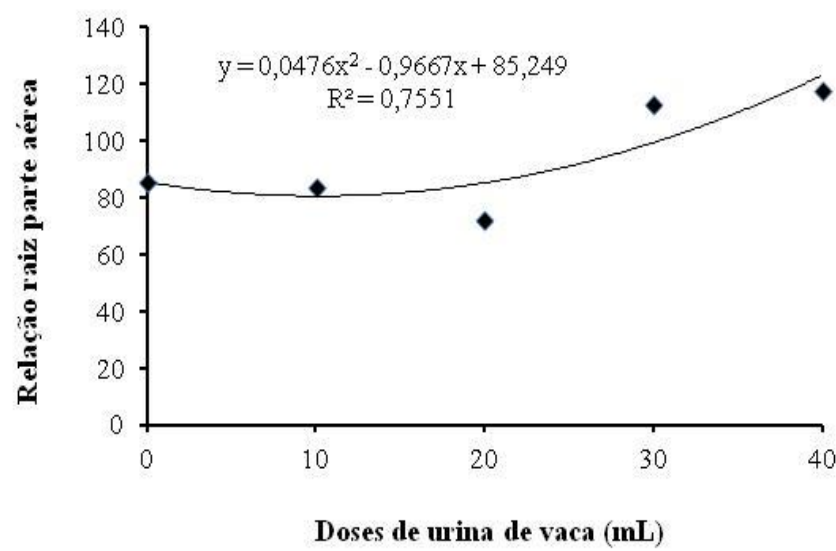

Figura 5: Efeito de doses de urina de vaca na relação raiz parte aérea de alface.

No que se refere às proporções de húmus de minhoca não foi observado efeitos significativos em nenhuma das variáveis analisadas, no entanto, as maiores médias foram obtidas com a maior proporção $\left(\mathrm{P}_{1}=50 \%\right.$ de solo $+50 \%$ de húmus de minhoca) (tabela 2$)$. Góes et al. (2012) utilizando húmus de minhoca na produção de mudas de tamarindeiro não obervaram efeitos significativos para o comprimento da raiz.

Tabela 2: Comprimento da raiz (CR), peso verde da folha (PVF), peso verde total (PVT), teor de água (TA) e relação raiz parte aérea (RPA) de alface sob proporções de húmus de minhoca.

\begin{tabular}{cccccc}
\hline \multicolumn{7}{c}{ Tratamentos } & CR & PVF & PVT & TA & RPA \\
\hline & $14,3 \mathrm{a}$ & $94,5 \mathrm{a}$ & $120,3 \mathrm{a}$ & $87,4 \mathrm{a}$ & $97,6 \mathrm{a}$ \\
$\mathbf{P}_{\mathbf{1}}$ & $13,4 \mathrm{a}$ & $94,6 \mathrm{a}$ & $113,9 \mathrm{a}$ & $88,4 \mathrm{a}$ & $91,4 \mathrm{a}$ \\
$\mathbf{P}_{\mathbf{2}}$ & &
\end{tabular}

$\mathrm{P}_{1}=50 \%$ de solo $+50 \%$ de húmus de minhoca e $\mathrm{P}_{2}=25 \%$ de solo $+75 \%$ de húmus de minhoca; Médias seguidas de mesma letra na coluna não apresentaram diferença estatística entre si. 


\section{CONCLUSÃO}

As mudas de alface responderam significativamente as doses de urina de vaca, com destaque na dose de $40 \mathrm{~mL}$. O húmus de minhoca não teve resposta significativa quando utilizado como substrato.

\section{REFERÊNCIAS}

ABREU, I. M. O.; JUNQUEIRA, A. M. R.; PEIXOTO, J. R.; OLIVEIRA, A. R. Qualidade microbiológica e produtividade de alface sob adubação química e orgânica. Ciência e Tecnologia de Alimentos, Campinas, v. 30 p. 108-118, maio 2010.

AQUINO, A. M.; LOUREIRO, D. C. Minhocultura. Embrapa Agrobiologia. Seropédica, RJ, 2004.

ARAÚJO NETO, S. E.; AZEVEDO, J. M. A.; GALVÃO, R. O.; OLIVEIRA, E. B. L.; FERREIRA, R. L. F.Produção de muda orgânica de pimentão com diferentes substratos.Ciência Rural, Santa Maria, v. 39, n. 5, p. 1408-1413, ago. 2009.

ARAÚJO, D. L. de; ALVES, L. de S.; VÉRAS, M. L. M.; ANDRADE, R. Desenvolvimento inicial do maracujazeiro sob fertilização orgânica e água disponível. ACSA - Agropecuária Científica no Semi-Árido, v. 10, n. 1, p. 128-133, jan - mar, 2014.

ARAÚJO, D. L. de; ALVES, L. de S.; VÉRAS, M. L. M.; ARAÚJO, D. L. de; ANDRADE, R. Níveis de água disponível e doses de urina de vaca no desenvolvimento do meloeiro cantaloupe. ACSA - Agropecuária Científica no Semi-Árido, v. 10, n. 2, p. 23-28, abr jun, 2014.

ARAÚJO, D. L. de; ALVES, L. de S.; VÉRAS, M. L. M.; ARAÚJO, D. L. de; ANDRADE, R. Desenvolvimento inicial do maracujazeiro sob fertilização orgânica e água disponível. ACSA - Agropecuária Científica no Semi-Árido, ACSA - Agropecuária Científica no Semi-Árido, v. 10, n. 1, p. 128-133, jan - mar, 2014.

ARTEAGA, M; GARCÉS, N.; NOVO, R.; GURIDI, F.; PINO, J. A.; COSTA, M.; PASOS, M.; BESÚ, D. Influencia de la aplicación foliar del bioestimulante Liplant sobre algunos indicadores biológicos del suelo. Revista de Protección Vegetal, La Habana, v. 22, n. 2, p. 110-117, 2007.

CRUZ, T. P.; JUNGER, L. A.; ZINGER, L. K. C. R.; SILVA, L. G.; PASSOS, R. R. Avaliação de cultivares de alface no município de Alegre - ES. Encontro latino-americano de iniciação científica, 15., encontro latino americano de pós-graduação, 11., 2011, Urbanova. Resumos... p.3.

FERREIRA, D. F. Sisvar Versão 5.0. Lavras: UFLA, 2007. 
GADELHA, R. S. S.; CELESTINO, R. C. A.; CARNEIRO G. M. Urina de vaca. On-line. Disponível em: <http://br.geocities.com/sociedade.alternativa/urina.html>. Acesso em: 29 jan. 2015.

GÓES, G. B. de; DANTAS, D. J.; ARAÚJO, W. B. M. de; COSTA e MELO, I. G.; MENDONÇA, V. Utilização de húmus de minhoca como substrato na produção de mudas de tamarindeiro. Revista Verde (Mossoró - RN - Brasil) v.6, n.4, p.125 - 131 outubro/dezembro de 2011.

MOESKOPS, B.; SUKRISTIYONUBOWO; BUCHAN, D.; HERAWATY, L.; HUSEN, E.; SARASWATI, R.; SETYORINI, D.; DE NEVE, S. Soil microbial communities and activities under intensive organic and conventional vegetable farming in West Java, Indonesia. Applied Soil Ecology, vol. 45, n. 02, p. 112-120, 2010.

OLIVEIRA, J. R.; XAVIER, F. B.; DUARTE, N. F. Húmus de minhoca associado a composto orgânico para a produção de mudas de tomate. Revista Agrogeoambiental, Pouso Alegre, v. 5, n. 2, caderno II, p.79-86, ago. 2013.

PEIXOTO, C. P.; PEIXOTO, M. F. da S. P. Dinâmica do crescimento vegetal (Princípios Básicos). Cruz das Almas. Nov. 2004.

PESAGRO-RIO (2002) Urina de vaca: alternativa eficiente e barata. Rio de Janeiro, Documentos, n. $96.8 \mathrm{p}$.

PIMENTEL GOMES, F. Curso de estatística experimental. Piracicaba: FEALQ, p. 541, 2000 .

RODRIGUES, M. L.; BATISTA, F. A.; NASCIMENTO, W. L.; VIEIRA, L. R.; RODRIGUES, R. C. Mudas de alface (Lactuca Sativa L.) produzidas com diferentes substratos orgânicos. In: Congresso Norte e Nordeste de Pesquisa e Inovação, 7, Palmas, 2012. Anais... Palmas - TO, 2012.

SILVA, E. M. N. C. P.; FERREIRA, R. L. F.; ARAÚJO NETO, S. E.; TAVELLA, L.B.; SOLINO, A. J. S. Qualidade de alface crespa cultivada em sistema orgânico, convencional e hidropônico. Horticultura Brasileira, vol. 29, n. 02, p. 242-245, 2011.

SOUZA, J. L. de; CASALI, V. W. D.; SANTOS, R. H. S.; CECON, P. R. Balanço e análise da sustentabilidade energética na produção orgânica de hortaliças. Horticultura Brasileira, vol. 26, n. 04, p. 433-440, 2008.

VÉRAS, M. L. M.; ALVES, L. de S.; ARAÚJO, D. L. de; ANDRADE, A. F. de; ANDRADE, R. Crescimento inicial da alface sob fertilização orgânica e volumes de húmus de minhoca. Revista Verde (Pombal - PB), v. 9, n. 2, p. 333-339, Abr -Jun, 2014.

VÉRAS, M. L. M.; ARAÚJO, D. L. de; ALVES, L. de S.; SILVA, T. H. da; ANDRADE, R. Efeito de substratos e fertilização orgânica em plântulas de pinheira. ACSA - Agropecuária Científica no Semi-Árido, v. 10, n. 1, p. 143-149, jan - mar, 2014.

VÉRAS, M. L. M.; ARAÚJO, D. L. de; ALVES, L. de S.; SILVA, T. H. da; ANDRADE, R. Efeito de substratos e fertilização orgânica em plântulas de pinheira. ACSA - Agropecuária Científica no Semi-Árido, v. 10, n. 1, p. 143-149, jan - mar, 2014. 